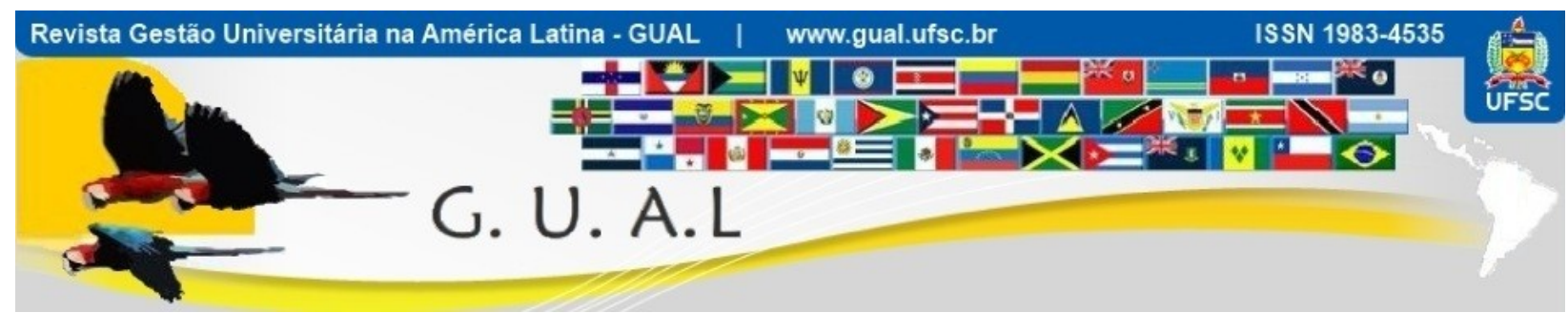

DOI: http://dx.doi.org/10.5007/1983-4535.2013v6n1p176

\title{
O PAPEL SOCIAL DA UNIVERSIDADE NO PREPARO PROFISSIONAL: UMA PESQUISA JUNTO AOS EGRESSOS DE ADMINISTRAÇÃO DA UNIOESTE - CASCAVEL
}

\section{UNIVERSITY SOCIAL ROLE IN PROFESSIONAL PREPARE: A SURVEY ALONG WITH GRADUATES OF ADMINISTRAÇÃO FROM UNIOESTE - CASCAVEL}

Loreni Teresinha Brandalise, Doutora Universidade Estadual do Oeste do Paraná - UNIOESTE lorenibrandalise@gmail.com

Cláudio Antonio Rojo, Doutor Universidade Estadual do Oeste do Paraná - UNIOESTE rojo_1970@hotmail.com

Débora Kasper, Graduada Universidade Estadual do Oeste do Paraná - UNIOESTE debora_kasper@hotmail.com

Almir Ferreira de Souza, Doutor Universidade de São Paulo - USP abrolhos@usp.br

Recebido em 09/novembro/2012

Aprovado em 16/janeiro/2013

Sistema de Avaliação: Double Blind Review

Esta obra está sob uma Licença Creative Commons Atribuição-Uso. 


\title{
RESUMO
}

Este estudo tem como objetivo demonstrar o papel social da universidade no preparo profissional do estudante do Curso de Graduação em Administração da Unioeste, campus de Cascavel. Assim, apresenta-se um projeto de pesquisa que se propôs ao acompanhamento da vida profissional dos ex-alunos do curso de Administração da Unioeste, campus Cascavel, como instrumento que possibilita uma continuada avaliação do curso e da instituição, por meio do desempenho profissional dos egressos. A partir disso, torna-se possível incorporar ao processo de ensino elementos da realidade externa já vivida pelos ex-alunos, tanto nos aspectos positivos, quanto nas dificuldades. Este trabalho foi realizado por meio da aplicação de questionários a uma amostragem de 27,65\% do total de egressos (308 bacharéis em administração), avaliando aspectos que indicam sua evolução profissional. A partir deste feedback a instituição é capaz de direcionar esforços no sentido de formar profissionais cada vez mais qualificados para enfrentar o mercado de trabalho, exercer as funções atribuídas e empreender na geração de riqueza.

Palavras-chave: Universidade. Competitividade profissional. Egresso.

\begin{abstract}
This study aims to demonstrate the university social role in the student's professional prepare of the student from AdmnistrationGraduate Course of Unioeste, Cascavel campus. Thus, it presents a research project that was proposed to follow the career of former students of Admnistration Course of Unioeste, Cascavel campus, as a tool that provides a continuous assessment of the course and institution through the professional performance of graduates. From this, it becomes possible to incorporate to the teaching process elements from external reality as experienced by former students, either on the positive aspects, as the difficulties. This work was performed through the application of questionnaires to a sample of $27.65 \%$ of total graduates (308 graduates in administration), evaluating aspects that indicate their professional development. From this feedback the institution is able to direct efforts in order to train professionals increasingly qualified to face the job market, performing the duties assigned and engage in generating wealth.
\end{abstract}

Keywords: University. Competitiveness professional. Egress. 


\section{INTRODUÇÃO}

Segundo Silva (2009a) a humanidade vive hoje uma revolução de proporções comparáveis às da Revolução Industrial. A nova sociedade que se delineia é a do conhecimento e da informação, na qual ciência e tecnologia são chave para o desenvolvimento econômico. Isto tem provocado um aumento nas conexões entre os envolvidos nos processos de produção e utilização do conhecimento científico, em particular entre empresas e universidades.

Ao longo de sua história, as universidades foram gradualmente assumindo o papel de centralizadora do conhecimento, fórum de debate e difusão de idéias. Seu sentido passa pela promoção do desenvolvimento social, por meio da instrução e estímulo criativo do ser humano que adquire conhecimento.

Vários fatores apontam que a capacidade de criar e trabalhar com o conhecimento pode garantir desenvolvimento sustentável, por isso, para construir um país que tenha, no século 21, autonomia de decisão sobre seus destinos, é essencial investir em seus recursos humanos, em educação, ciência e tecnologia. Educar as pessoas capazes de trabalhar com o conhecimento é fundamental para uma nação.

Não somente para criar e transmitir o conhecimento científico, mas também para usar, transformar e aplicar conhecimento, são necessários profissionais qualificados e capazes de aprender continuamente, principalmente em momentos de profundas transformações, como o de agora (VOGT, 2004).

Sabe-se que em décadas passadas, a qualificação profissional adquirida através da educação, era um critério qualificador de competição no mercado de trabalho. Hoje, o profissional de sucesso não é mais aquele que possui somente um conhecimento específico em dado assunto, o mercado está exigindo uma visão globalizada que atenda um consumidor cada vez mais exigente.

A universidade tem o papel de gerar saber e conhecimento que devem contribuir para provocar transformações na própria sociedade em que está inserida, ao mesmo tempo, o curso de administração, que está muito relacionado ao processo de desenvolvimento do país, ganha cada vez mais espaço, enquanto proporciona aos acadêmicos uma visão ampla dos processos e tem um vasto campo de atuação. 
Dessa forma, o objetivo deste estudo é demonstrar o papel social da universidade no preparo profissional do estudante do Curso de Administração da Unioeste - campus de Cascavel.

\subsection{JUSTIFICATIVA}

É importante focalizar a universidade com atenção, por suas características distintas, dentre as quais a valorização da cultura e a constatação de que, além de dever-se a ela, a melhor formação disponível na graduação, ela é, quase exclusivamente, responsável pela formação pós-graduada e pela pesquisa, constituindo o patrimônio mais importante de que se dispõe para implementar projetos estratégicos de desenvolvimento regional e nacional (CRUZ, 2001).

Segundo MEC (apud ROJO, 2006) com o Exame Nacional dos Cursos (ENC), que ficou mais conhecido pelo nome de Provão, depois substituído pelo Enade, o MEC começou a demonstrar para a sociedade que a educação estava sendo avaliada, e isso gerou expectativas no mercado. Soma-se ainda a avaliação das condições de ensino (ACE), que avalia a ação didático-pedagógica, o corpo docente e as instalações dos cursos. Isso mostra que este é um momento de crescimento no setor educacional, especialmente do ensino superior, o que leva à competitividade.

O curso de Administração na Unioeste foi implantado em Cascavel, em 1976 e caminha com a história da universidade, tendo como objetivo formar profissionais gestores de organizações, analíticos da realidade e aptos a avaliar, liderar, tomar decisões, gerir, criticar, refletir, pesquisar e promover organizações públicas e privadas. Além disso, dever ser capaz de controlar o funcionamento de empresas e instituições públicas e privadas, por meio de atividades de chefias gerais e setoriais, de assessoramento e consultoria, buscando o aprimoramento das organizações.

Administrar é algo muito mais abrangente do que se imagina, não basta experiência, é preciso determinação, conhecimento e preparo. Administrar é dar uma direção o tempo todo, é inovar, é cuidar da 'saúde' da organização sem deixar de olhar para fora e enxergar a organização como agente de transformação na sociedade.

Em 2006 o curso de Administração na Unioeste completou 30 anos de história e alcançou nota máxima no Enade (nota 5), nota esta alcançada por apenas 13 dentre as 3537 instituições de ensino superior que ofertam o curso no país (MEC/INEP, 2009), percebeu-se 
então a necessidade de buscar informações a respeito dos egressos, ou seja, os ex-alunos do curso.

Partindo dessa ideia, o professor Dr. Claudio Antonio Rojo, docente da Unioeste, desenvolveu um projeto de pesquisa para que se conhecesse o resultado dos trabalhos na formação profissional. Este estudo visa descrever a evolução profissional dos egressos do curso de Administração da Unioeste- campus de Cascavel, a fim de se conhecer a utilização da sua formação na atuação na sociedade e que se possa obter um retorno de como o ensino influenciou na evolução da carreira profissional do egresso.

O conhecimento destas variáveis oportunizam melhorias na qualidade de ensino e na comunicação dos casos de sucesso dos egressos, podendo motivar os alunos matriculados e futuros ingressantes com a construção de uma imagem ainda mais positiva.

Considerando que o aluno de hoje está visivelmente preocupado com a sua inserção no mercado de trabalho e com a imagem da escola que frequenta, as instituições de ensino superior devem adaptar suas estruturas a essas novas exigências para continuar no mercado.

Nesse sentido, Rojo (2006) considera que o que caracteriza como um fator forte para a construção da imagem das Instituições de Ensino superior, é o bom egresso. O egresso com sucesso na carreira pode ser a própria imagem da instituição perante a sociedade e a concorrência profissional.

\section{UNIVERSIDADE \& DESENVOLVIMENTO}

No último quarto de século, o sistema de ensino superior cresceu em número de instituições e número de alunos, afirma Niskier (1997). Entretanto, segundo este autor, citado por Canopf, Festinalli e Ichikawa (2005), este dado não reflete existência de qualidade e competência. Existem altos e baixos do ensino superior que distanciam as universidades de uma regularidade, pois há uma baixa frequência aos cursos, baixa avaliação do aprendizado e baixa qualidade de ensino.

De acordo comAzzi (2007), as grandes alterações do mercado de trabalho estão associadas a mudanças no perfil da mão-de-obra. NoBrasil, apenas $10 \%$ dos jovens conseguem concluir o ensino médio e ingressar numa Universidade na faixa etária adequada para tal, que está compreendida entre os 18 e 24 anos de idade. A educação e a formação profissional, juntamente com suas relações com o desenvolvimento do país, tornaram-se temas principais no mundo do trabalho. 
Todos os níveis do mercado, principalmente o executivo, estão se defrontando com desafios diferentes dos habituais, exigindo dos profissionais uma busca por conhecimentos diferenciados, que, por muitas vezes, precisam ser revistos.Ou reciclados, adaptando suas habilidades ao mercado que se encontra tão tumultuado e competitivo.

A expansão de empresas nacionais e internacionais intensificou a demanda por profissionais qualificados para tomadas de decisão organizacional, ao contrário da década de 1950 quando "os aspectos mais enfatizados na formação dos administradores eram o conhecimento e habilidades técnicas, mas apropriadas para a execução de atividades impostas pelas organizações de negócios" (CANOPF, FESTINALLI e ISHIKAWA, 2005, p. 80). Nas décadas de 1960 e 1970 houve uma rápida expansão do ensino superior em Administração, incentivada pelos mesmos fatores de implantação dos cursos (LOPES, 2002; NICOLINI, 2001).

De acordo com a pesquisa nacional do sistema CFA/CRAs, o curso de Administração agrega o maior número de alunos matriculados no ensino superior. Mello, Melo Jr e Mattar (2011, p.27) citando o INEP/MEC (2010) afirmam que em 2005 existiram 643.158 matriculados, aumentando para 846.493 em 2010. Esse universo representa 18\% de matriculados. A graduação em Administração lidera a lista dos dez cursos mais procurados pelos candidatos ao ensino superior no país.

Contudo, Lima (2002) alerta que, sem se atualizar, qualquer profissional será descartado, tenha ele 70 ou 25 anos de idade. Os administradores devem se responsabilizar pelo próprio aprendizado e estar conscientes que o seu desenvolvimento pessoal e profissional depende, quase que exclusivamente, das suas ações pessoais na busca de novos conhecimentos, mesmo os profissionais mais antigos. As pessoas têm a capacidade de se atualizar, de surpreender e de virar o jogo.

A discussão que permeia a educação profissional hoje é possibilitar que uma pessoa, se empregada, mantenha o emprego e, se desempregada, consiga trabalho. Mas, sabe-se que a qualificação profissional aumenta as chances do trabalhador, pois o torna mais apto para exercer o trabalho com maior probabilidade de êxito. $\mathrm{O}$ aluno que se prepara para o mercado com uma capacitação formal tem mais chances de ser reconhecido como competente e amplia a possibilidade de geração de renda. No entanto, embora a educação profissional seja apontada como um direito, ela não garante emprego, devido às drásticas mudanças no nível geral de emprego a partir da década de 1990 (CRUZ, 2001). 
Isso faz com que a exigência de qualificação e a maior competitividade apresentem um lado 'perverso'. A formação profissional se transforma em um critério de seleção e não necessariamente uma exigência do setor de produção, pois toda empresa, não importa o tamanho, é uma representação da sociedade, e, como tal, está em constante mudança. Nem mesmo o profissional qualificado está isento de pressões. Para manter-se no emprego, o trabalhador com alto nível de instrução necessita de constante atualização, o que vem sendo chamado de educação continuada (VOGT 2004).

De acordo com Santos (2008), a teoria econômica considera a formação profissional como um investimento no capital humano, e essa concepção nasceu da necessidade de planejar e racionalizar os investimentos do Estado no que diz respeito à educação escolar. Conforme essa teoria, os investimentos na formação profissional conduzem a um aumento da produtividade do trabalhador.

Neste contexto, sabe-se que o novo ambiente empresarial provoca a necessidade de as empresas entenderem que o tempo de aprender tornou-se permanente. Por mais que se desenvolvam metodologias para desenhar cenários, está cada vez mais difícil planejar o futuro de forma segura e com um mínimo de risco. Para isso, uma série de mudanças devem acontecer, sobretudo no perfil do administrador. Dada as repercussões do seu trabalho, ele deve se considerar um eterno aprendiz e estar atento a todas mudanças.

Essa necessidade crescente de capacitação e qualificação diferenciada dos profissionais também exige evolução do processo educativo, pois a escolarização precária acaba sendo um entrave para o desenvolvimento da sociedade baseada no conhecimento formal.Buarque, citado por Rinaldi(2002), afirma que o caminho da humanidade seja ele qual for, passa pela Universidade que deverá se transformar, buscando flexibilidade e agilidade para atuar de uma forma mais efetiva. Não são mais aceitos processos decisórios morosos, estruturas inchadas e infindáveis jogos de poder.

O aprendizado deve estimular os profissionais da área de administração a aprenderem com suas experiências, uma vez que o conhecimento gerencial não é algo totalmente mensurável e engloba habilidade, arte e ciência (MINTZBERG, 2006).

De acordo com Gasset (1999), uma forma de compreender a Universidade é tendo em vista que esta é um centro de estudos, pesquisa e extensão que se caracteriza pela sua dimensão, transmissão de experiência cultural e científica, capaz de alargar a mente e amadurecer a imaginação das pessoas para a aventura do conhecimento na sociedade e que 
possui ampla capacidade de representação social, cultural e intelectual.

Para este autor, uma escola de formação de profissionais é um dos instrumentos mais amplos e mais profundos de elaboração e transmissão da cultura comum brasileira, dada a sua abrangência experimental e científica. É uma instituição social de interesse público e um importante instrumento para o desenvolvimento da educação, da saúde, da cultura e da economia do país. Assim, o papel da universidade é único, pois a formação de pessoas dotadas de um refinamento do conhecimento passa pela educação formal, sendo que sua evolução depende da constante atualização e aprimoramento das técnicas que perfazem o perfil profissiográfico da formação do cidadão dotado de sustentação científica.

Closs e Antonello (2008) afirmam que o papel dos administradores deve ser o de agir como facilitadores de mudanças, envolvendo a capacidade de liderar favorecendo a motivação e a autoconfiança e ao mesmo tempo, tendo uma visão abrangente que o permita dividir as responsabilidades e compartilhar poder, podendo lidar com situações de instabilidade e ser capaz de corresponder às novas demandas. Dessa forma, o aproveitamento das experiências de mudanças provoca crescimento, preparando-os para enfrentar diversas situações do cotidiano.

Partindo desses pressupostos, também se pode analisar a universidade como diferencial na carreira profissional dos que ali passam, ela se torna ponto de referência em um mundo altamente concorrido.

A Universidade não pode mais ser conivente com a administração empírica, pondera Ribeiro (1977). A complexidade da organização universitária começou a exigir a aplicação de conhecimentos científicos como estratégia de atuação. A instituição universitária tornou-se um órgão bastante burocratizado, com altos níveis de formalização nos processos decisórios. Por isso percebe-se que a Universidade tem necessariamente de criar condições para a autorealização do estudante.

Segundo Rojo (2006), as possibilidades de sucesso de um concorrente dependem de fatores como a informação e a capacidade de utilização dessa informação para a tomada de decisão. Em se tratando de planejamento, quanto maior o número de informação de determinados fatores essenciais na atuação do seu mercado, maior é a possibilidade de acerto aos objetivos traçados.Atualmente o papel da universidade não consiste apenas em formar os que mais tarde tomarão parte na sociedade. Por meio da pesquisa científica produzem-se novos conhecimentos que se tornam essenciais nos processos administrativos. 
Na visão de Gracioso (1995), a percepção que o público-alvo tem de determinada instituição é o reflexo do posicionamento escolhido percebido, isto é, a sua imagem. Da mesma forma, uma imagem condizente com o posicionamento estratégico torna-se um fator importante de reforço estratégico.

Nesse diapasão, Silva (2009b) diz que as evidências mostram que somente empresas que compreendem claramente sua própria competência e necessidade tecnológica conseguem estabelecer ligações maduras e duradouras com a Universidade e obter ganhos reais com estas ligações. Por outro lado, somente quando a Universidade tem uma missão e objetivos explicitamente comprometidos com a produção, disseminação e transferência de conhecimento e processos organizacionais que suportem esta transferência de forma profissional e empreendedora, ela pode estabelecer ligações também maduras e duradouras com as empresas.

Por isso, a trajetória de cada indivíduo fica condicionada a uma série de fatores e aqueles mais bem preparados têm condições de construir mecanismos para alcançarem seus objetivos de forma mais eficiente. Dentre as tantas atividades e papéis da universidade, o ensino se torna a própria imagem institucional quando os alunos, então profissionais, são bem-sucedidos, pois a percepção de qualidade da instituição pela sociedade acaba sendo refletida na imagem do profissional egresso.

\section{METODOLOGIA}

Para que os objetivos pudessem ser alcançados, foram utilizados mecanismos que auxiliaram a coleta dos dados necessários à pesquisa. Sendo assim, estruturou-se um questionário que foi aplicado a 308 bacharéis no ano de 2009, que correspondem a 27,65\% do universo da pesquisa. Tendo em vista que já se passaram 30 anos desde o início do Curso de graduação em Administração na Unioeste, observou-se uma grande dificuldade: Como encontrar tantos egressos tendo apenas os números de telefone de turmas mais recentes?

A partir disso, iniciou-se intensas buscas com os telefones já listados, e que inúmeras vezes haviam sido mudados, sites de busca, sites de auxílio à lista, conversas com os próprios colegas de turma que mantém contato, listas de e-mail e comunidades virtuais.

Ao entrar em contato com o egresso foi aplicado o questionário buscando identificar: perfil pessoal; organizações onde atuam; atividades que desenvolvem; sugestões e críticas quanto à formação; adequação do curso ao mercado de trabalho; comportamento em relação à 
educação continuada; diferenças na formação e atuação. Este questionário foi respondido via telefone ou e-mail.

A metodologia da pesquisa utilizada é a exploratória com base no levantamento de dados primários e secundários. As fontes secundárias consistem de bibliografia e registros dos dados oficiais da Unioeste, campus Cascavel, desde a sua fundação como Fecivel. O instrumento de coleta de dados primários da pesquisa foi o questionário de avaliação qualitativa, aplicado aos egressos de Administração da Unioeste.

A pesquisa é do tipo descritiva, pois, de acordo com Marconi e Lakatos (2003), possibilita descrever as variáveis apontadas para o estabelecimento das relações entre si. Quanto ao processo de raciocínio, o tipo é indutivo, o qual dá condições oportunas para a obtenção de conclusões que podem ser generalizadas a partir de observações e mensurações de uma série de dados, conforme afirmam Cervo e Bervian (2003).

Os métodos utilizados para a realização da pesquisa são o dedutivo e o estudo de caso. O dedutivo pressupõe que o referencial teórico existente dos assuntos correlatos disponíveis serve de base para as considerações, o que caracteriza a pesquisa como do tipo bibliográfica. Já o estudo de caso pode ser considerado como representativo de muitos outros, para que a aplicação do modelo proposto venha a ser validada (MARCONI e LAKATOS, 2003).

A análise dos dados obtidos foi feita por meio de apresentações visuais para análise conjunta, por se tratar de análise com características setoriais com participantes de um grupo que tornam difusas as conglomerações de atributos por aproximação de formatação nas diversas áreas do conhecimento que compõe a Universidade.

Este estudo foi apresentado e publicado nos Anais V Encontro Paranaense de Pesquisa e Extensão em Ciências SociaisAplicadas e VIII Seminário do Centro de Ciências Sociais Aplicadas, em 2010.

\section{O CASO DOS EGRESSOS DO CURSO DE ADMINISTRAÇÃO DA UNIOESTE - CAMPUS CASCAVEL}

O curso iniciou suas atividades no ano de 1976. Do ano de formação da primeira turma, 1980, até o ano de 2006, formou-se 1114 bacharéis em administração, sendo este o universo da pesquisa. Através da aplicação de 308 questionários representando uma amostragem de $27,65 \%$ dos egressos formados, obtiveram-se os resultados apresentados nesta seção.

Em relação à distribuição dos egressos de acordo com o sexo, nota-se que há 
praticamente uma situação de igualdade em relação aos administradores do sexo masculino e feminino. Através disso, é possível ressaltar a tendência real que traz uma maior participação feminina no curso de administração, e no mundo dos negócios como um todo, como se vê no Gráfico 01.

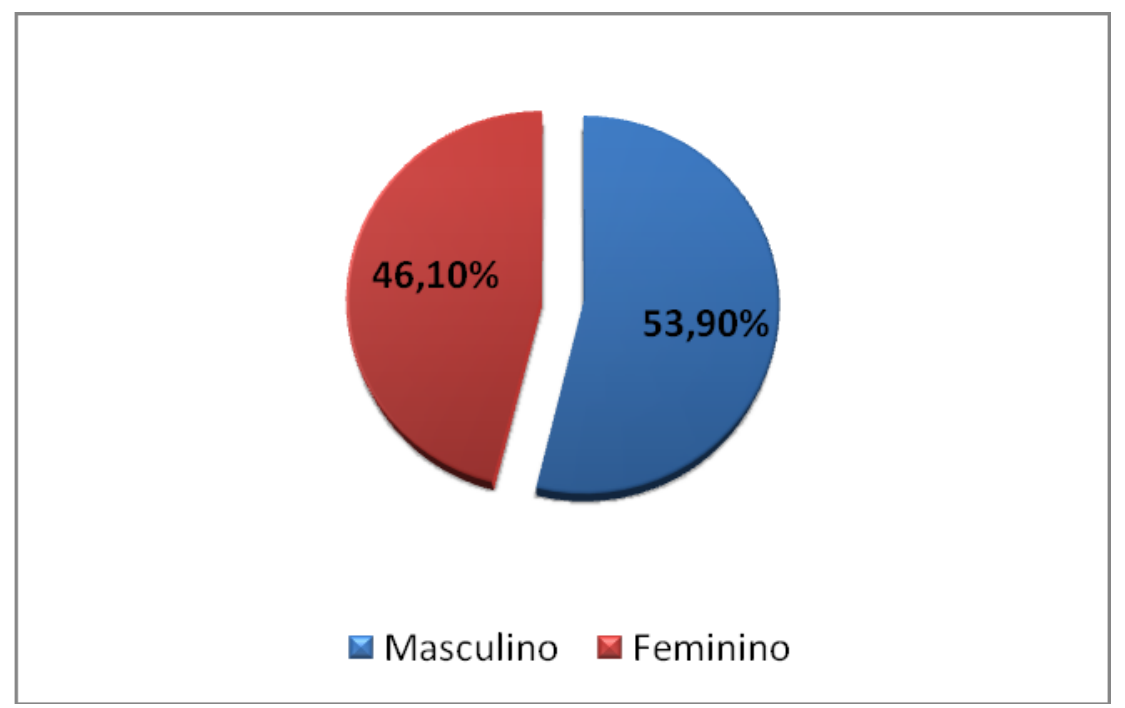

Gráfico 01 Distribuição dos egressos por sexo

O Gráfico 02 mostra os resultados obtidos quanto à formação continuada dos egressos.

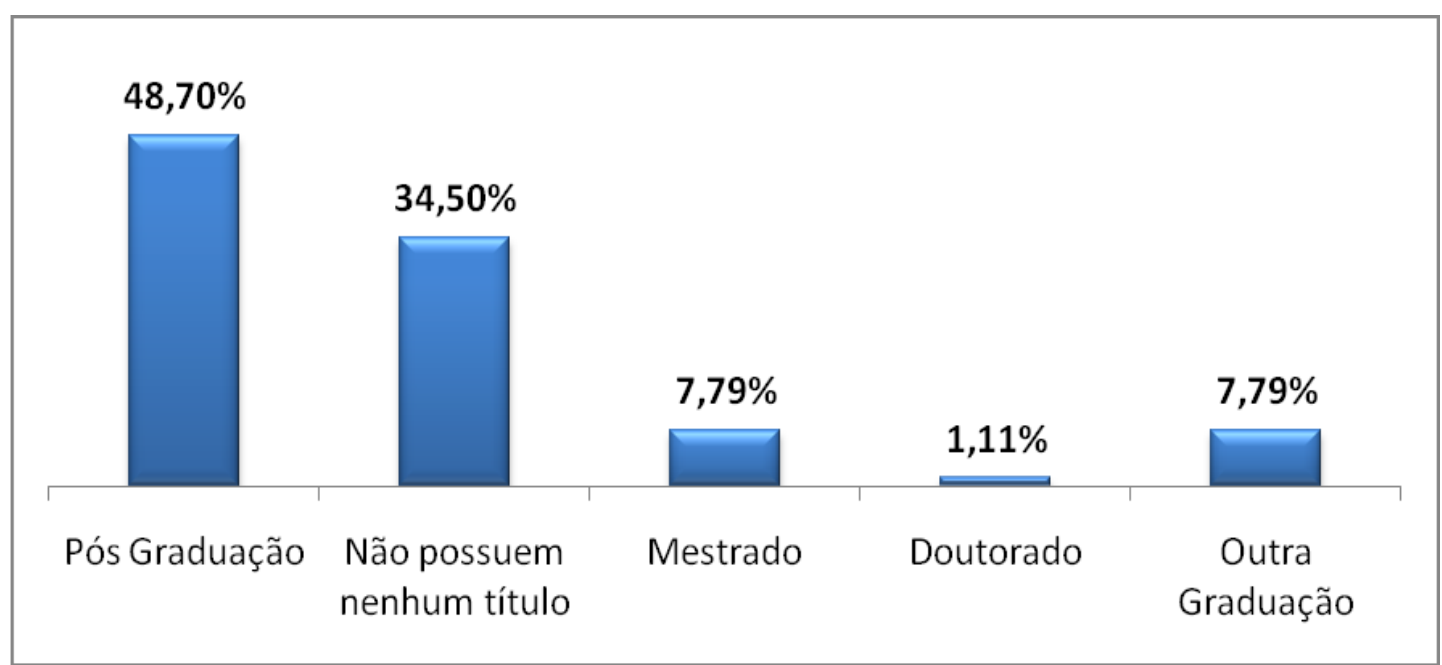

Gráfico 02 Títulos de pós-graduação

O contingente de administradores casados é de $61,04 \%, 33,44 \%$ deles encontram-se solteiros, $4,54 \%$ dos egressos são divorciados, $0,32 \%$ são viúvos e $0,64 \%$ consideraram a opção 'outro'.

Questionados se dominam alguma língua estrangeira, constatou-se que ainda é baixo o domínio de idiomas estrangeiros pelos egressos $(38,8 \%)$, sendo que dentre aqueles que 
dominam algum idioma, $21 \%$ disseram dominar o inglês, 7,1\% o espanhol, 5,3\% inglês e espanhol, $3,6 \%$ o italiano, $0,9 \%$ o inglês e o francês, $0,6 \%$ o alemão, e $0,3 \%$ dos egressos disseram dominar o inglês, espanhol, alemão e árabe.

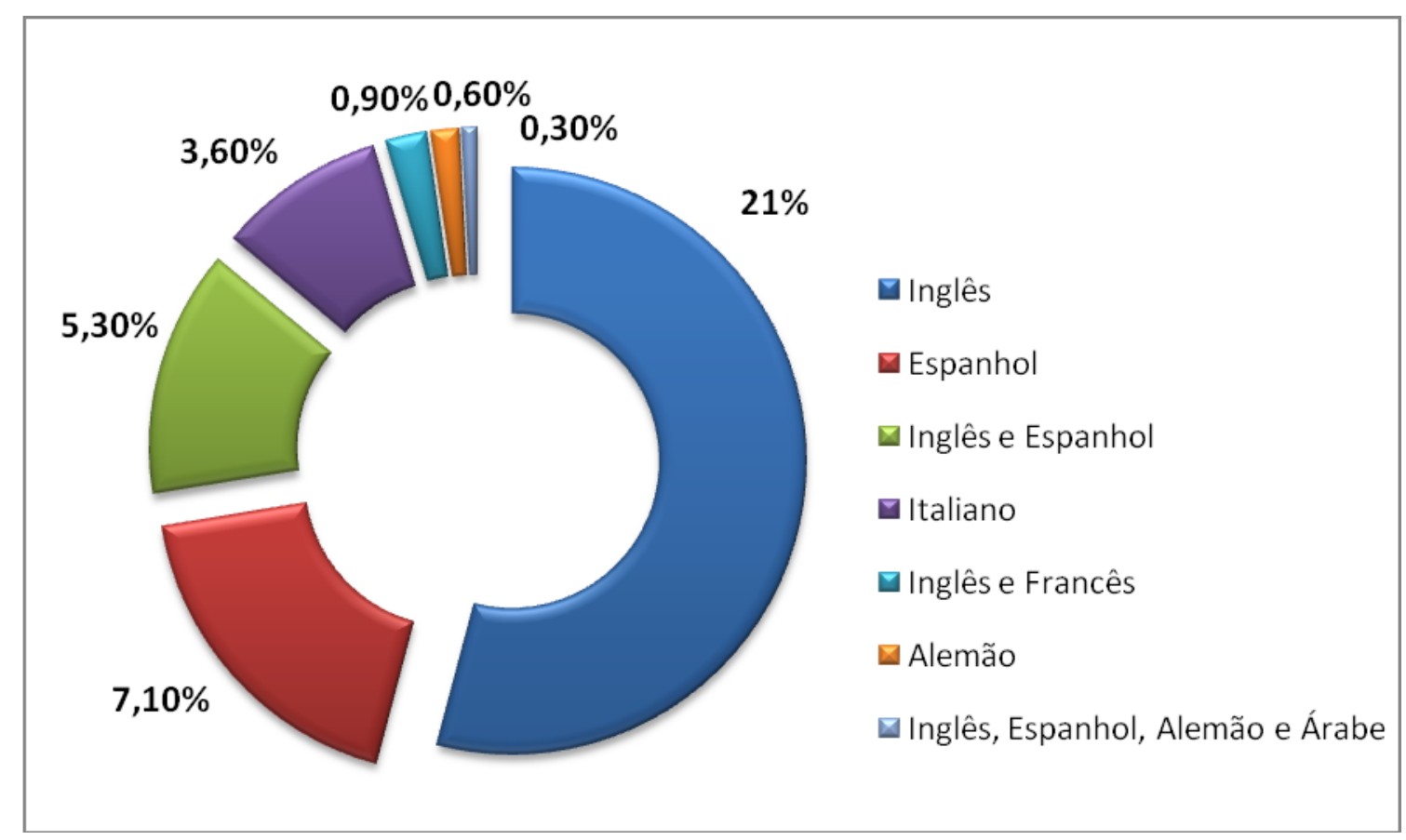

Gráfico 03 Domínio de idiomas pelos egressos

Outro fato importante é que $83,12 \%$ dos egressos tiveram sua primeira atividade profissional antes de iniciarem o curso de graduação, e isso mostra que o contato com o mercado de trabalho quase sempre acontece antes de haver uma qualificação específica. Outros $15,91 \%$ dos egressos tiveram sua primeira atividade profissional durante a graduação e apenas $0,97 \%$ deles tiveram a primeira atividade profissional após terem se formado.

Levando em consideração as atividades realizadas durante a graduação, percebe-se que a maioria dos egressos $(60,95 \%)$ não participou de nenhuma atividade relacionada a projetos de pesquisa, iniciação científica, empresa Júnior, movimentos estudantis (DCE) ou monitoria. Em contrapartida, dentre os que participaram de alguma destas atividades, a maioria $(15,05 \%)$ participou da Empresa Junior, outros 10,65\% participaram de projetos de pesquisa, apenas $3,85 \%$ dos egressos realizaram iniciação científica e 9,47\% dos egressos participou de movimentos estudantis (DCE).

Pesquisou-se ainda como se encontra a atual situação dos egressos no mercado de trabalho, o que pode ser facilmente visualizada no Gráfico 04. 


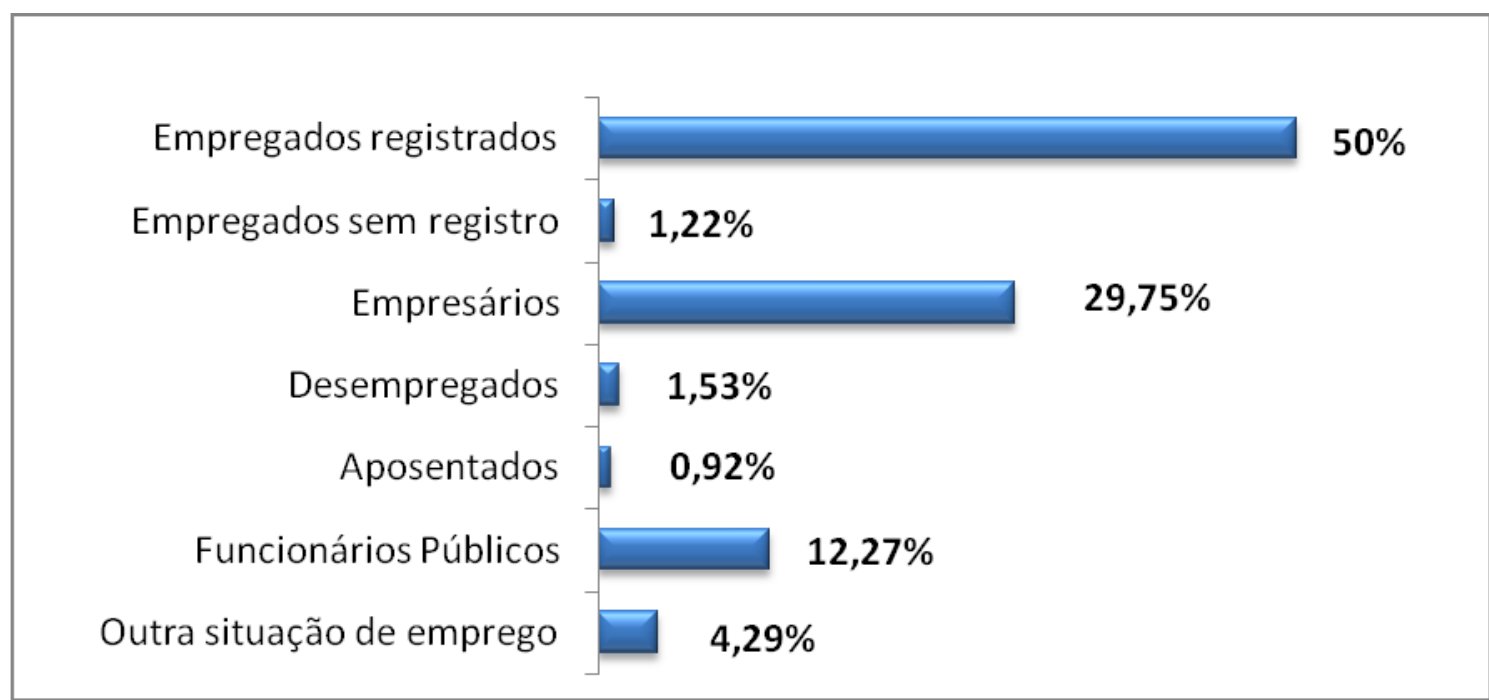

Gráfico 04 Atual situação dos egressos no mercado de trabalho

Em relação às maiores dificuldades encontradas depois de formados, tem-se o seguinte resultado: a maioria (31,69\%) dos egressos do Curso de Administração não encontrou nenhuma dificuldade relevante depois de formados, 16,66\% afirmam que a alta concorrência é a maior dificuldade encontrada, para 9,29\% dos egressos a maior dificuldade é a falta de experiência profissional e $8,74 \%$ consideram a falta de conhecimento de outros idiomas uma dificuldade relevante e na mesma porcentagem acreditam que outro fator atrapalhador foi a falta de conhecimento em relação ao mercado de trabalho. Outra dificuldade encontrada por $3,82 \%$ dos egressos foia falta de conhecimento teórico, e por fim, 21,31\% dos egressos tiveram outras dificuldades depois de formados.

O setor da economia em que os egressos trabalham atualmente varia bastante: $30,68 \%$ deles trabalham no setor de serviços, $16,16 \%$ no comércio, $10,14 \%$ trabalham com ensino e educação, 11,5\% trabalham em órgãos governamentais, 11,51\% trabalham em indústrias, $4,38 \%$ trabalham com consultoria, 3,84\% trabalham em empresas estatais, $0,27 \%$ dos trabalham na área de terceiro setor. Apenas $4,93 \%$ dos egressos trabalham com agronegócios, e $6,57 \%$ trabalham em outros setores da economia.

Pesquisou-se sobre a renda dos egressos antes, durante e depois de realizarem oCurso de Administração. Os Gráficos 05 e 06 mostram que o percentual dos egressos que ganhavam até 5 salários (antes da graduação) aumentou 7,44\% durante o curso. 


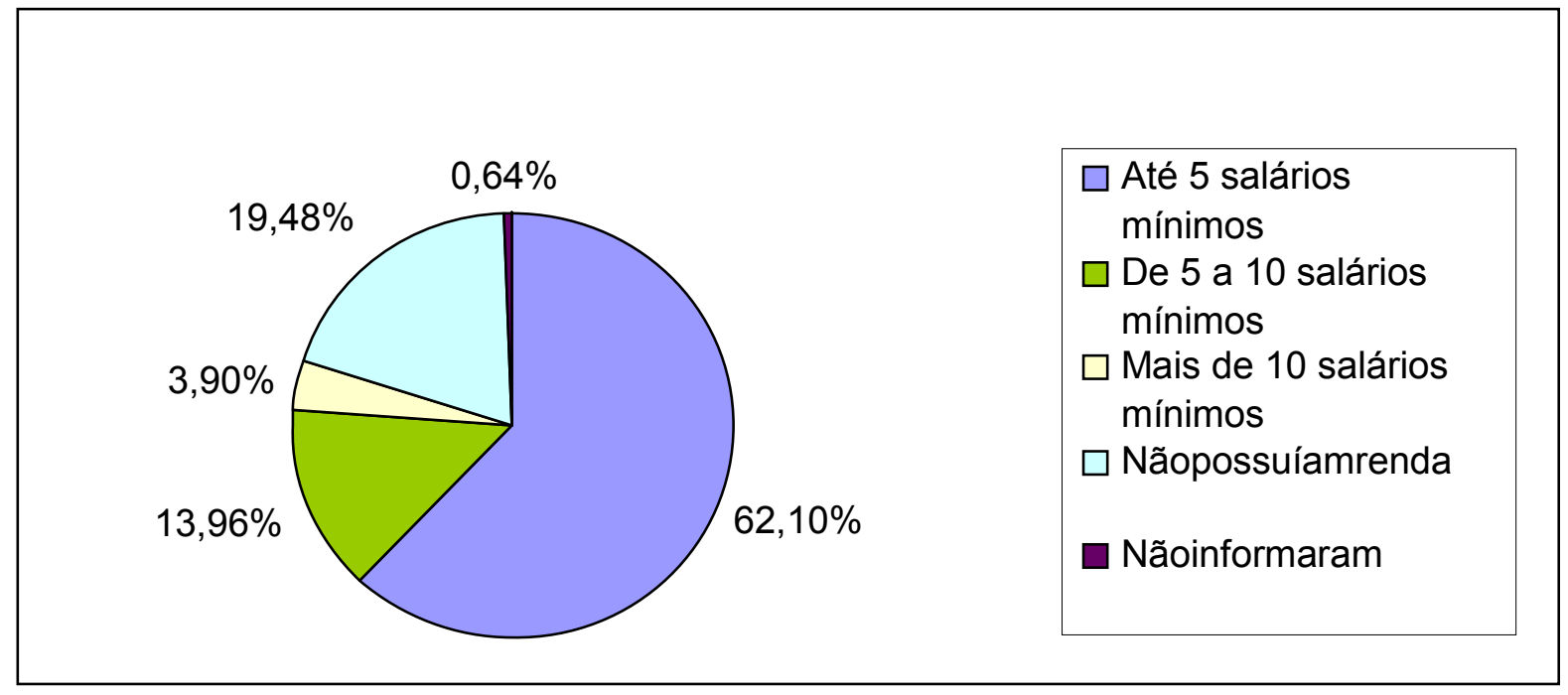

Gráfico 05 Renda dos egressos antes de iniciarem o curso

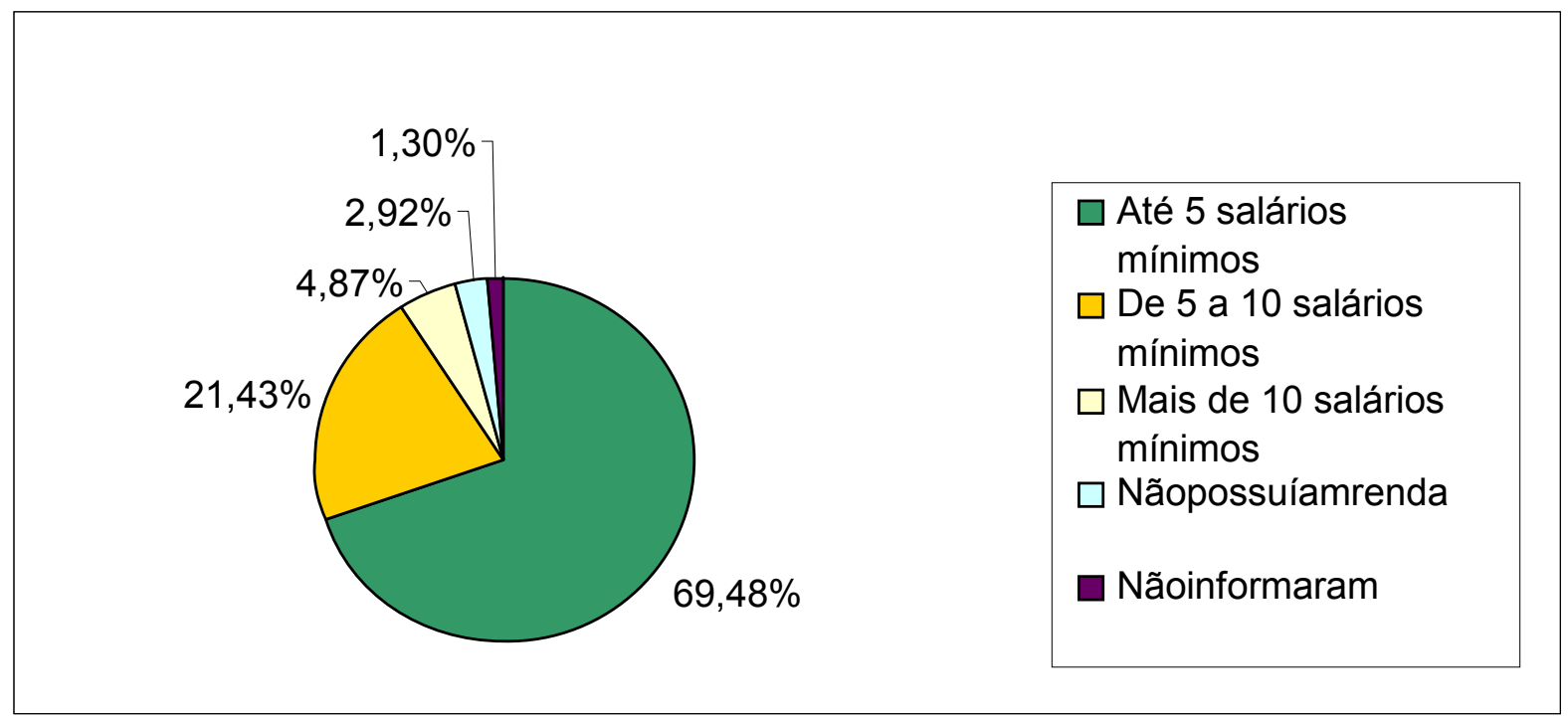

Gráfico 06 Renda dos egressos durante o curso de graduação

O Gráfico 07 mostra que depoisde formados, sem considerar a evolução dos dados no tempo, de 69,48\% dos egressos que possuía renda até 5 salários mínimos, apenas 22,07\% continuaram nesta faixa salarial.43,18\% possui renda de 5 a 10 salários mínimos, $31,17 \%$ dos egressos possui renda de mais de 10 salários mínimos. Apenas $0,33 \%$ não possuí renda e $3,25 \%$ dos egressos não responderam. 


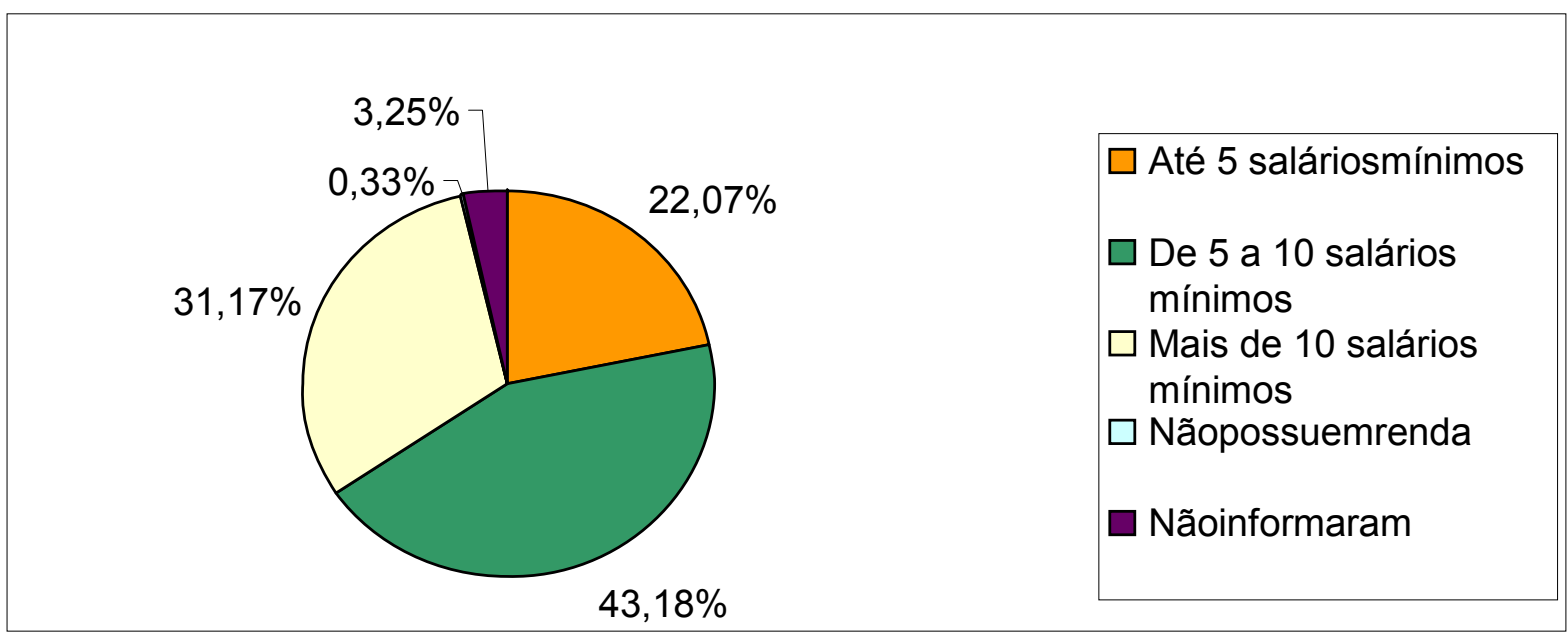

Gráfico 07 Renda dos egressos depois de formados

O Gráfico 08 compara a faixa salarial dos egressos, mostrando a evolução da renda antes, durante e depois da graduação em Administração.

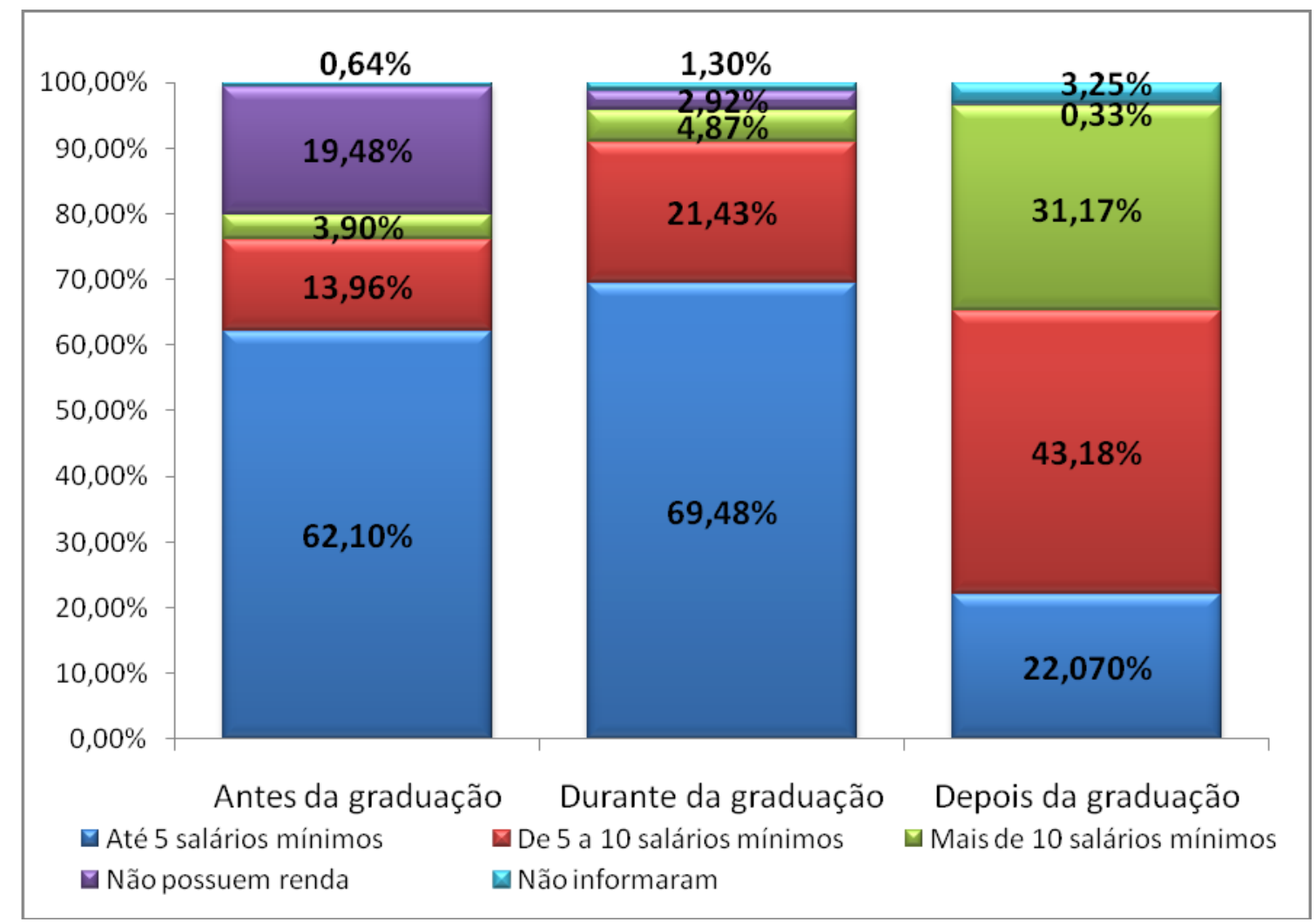

Gráfico 08 Comparativo de renda dos egressos antes, durante e depois de formados

Pelos resultados da pesquisa percebe-se que a situação dos egressos melhorou do ponto de vista financeiro. O número de egressos que se encontra na faixa salarial de 5 a 10 salários mínimos cresceu 7,47\%. O número de egressos que frequentava o curso subiu 
$21,75 \%$ depois que se formaram. O percentual dos egressos que ganhavam mais de 10 salários mínimos antes de iniciar o curso também aumentou $0,97 \%$ durante a graduação e mais $26,3 \%$ depois que os egressos se formaram.

\section{CONSIDERAÇÕES FINAIS}

A universidade e as organizações têm seus papéis distintos e, ao mesmo tempo, complementares na sociedade. Os papéis são claramente definidos e por muito tempo via-se como uma relação entre produtor e consumidor, no entanto, isso tende a mudar, pois a necessidade de interação entre as duas se torna cada vez mais constante diante do mundo em que vivemos e das limitações que lhes são impostas. A universidade buscando cada vez mais tornar a teoria o mais aplicável possível, e as organizações tentando aproximar-se de novos conhecimentos.

Ao mesmo tempo, as organizações devem incorporar novos valores e dominar conceitos filosóficos, sociais e políticos, abandonando o tecnicismo, uma vez que sua simplicidade acabaria inibindo a capacidade de adaptação das organizações.

Essas relações podem ser estabelecidas quando algo que acontece na empresa é estudado e analisado na universidade com o objetivo de identificar as mudanças econômicas ou sociopolíticas que podem ter desencadeado tal fato. Isso traz oportunidades de analisar todo o contexto da situação para que se melhore no futuro.

Neste contexto, para ser bem sucedida, uma instituição educacional deve lidar efetivamente com seus públicos e gerar alto nível de satisfação, pois estes públicos tornam-se os melhores divulgadores da instituição.

O ambiente de negócios nunca foi tão dinâmico, competitivo e imprevisível como neste início de século, o que exige uma maior flexibilidade das organizações e novos modos de definição das estratégias que orientarão as ações empresariais. Modernizar depende de mudanças no próprio modo de pensar e agir nos ambientes sociais da vida cotidiana e cívica. Nesse contexto, a universidade também está presente e como tal, deve seguir suas diretrizes neste mesmo sentido.

No entanto, percebe-se que a principal dificuldade da universidade não se encontra fora dela, mas em seu próprio interior: as práticas obsoletas, a dificuldade em adequar-se a um novo contexto de relações sociais em um mundo economicamente complexo e processos decisórios lentos que, frequentemente, acontecem em decorrência de um conservadorismo 
persistente. Em consequência, estas dificuldades reduzem seu potencial inovador e criativo e prejudicam sua função como parte do nervo central de transformação do mundo social por meio da educação, do conhecimento e da ciência.

Por isso, as universidades precisam estar atentas ao ambiente em constante mutação que exige da habilidade dos dirigentes a avaliação e desenvolvimento do melhor meio ou os cursos de ação para lidar com as contingências, de modo a promover a manutenção do equilíbrio ao mesmo tempo em que se exige uma maior sensibilidade em relação às ações realizadas e ao modo como estas influenciam o ambiente acadêmico.

Este tipo de avaliação tem uma importância ímpar, principalmente em um momento de crise como este que vivemos hoje. Ao passo que um modo de produção do conhecimento mais dinâmico está sendo exigido das Universidades e seu papel de transmissão do conhecimento também.

A universidade deixa de ser algo à parte na sociedade somente voltada a certos níveis da sociedade e torna-se algo extremamente presente na vida das pessoas como um todo, o que torna seu papel social muito ativo.

Da mesma forma, as buscas e necessidades dos seres humanos seguem caminhos semelhantes, pois se sabe que nas décadas de 1960 e 1970, a maioria das pessoas almejavam trabalhar em uma grande empresa estatal, privada ou multinacional. Aquelas que tiveram a oportunidade de frequentar um curso superior certamente se prepararam para assumir uma função técnica ou gerencial dentro de uma empresa na condição de empregadas. Pouco ou nenhum estímulo foi dado aos estudantes para que considerassem a opção de criar um negócio próprio.

Com o passar do tempo, essa realidade começou a mudar, principalmente a partir do momento em que o avanço científico e tecnológico fez surgir novas técnicas, processos e métodos, que consequentemente automatizaram o trabalho, eliminando empregos. A partir daí a busca por novas alternativas de emprego foi e ainda é, constante. Esta tem se tornado uma questão social de extrema relevância, pois para lidar com a crise do emprego, muitos tenderão a criar um auto-emprego, isto é, gerar oportunidades próprias de trabalho por meio da criação de pequenos negócios.

Assim, baseadas na hipótese de que ser dono de um negócio constitui, para o indivíduo, uma alternativa de criação de seu próprio emprego e o de outras pessoas no 
contexto atual, as esferas governamental e educacional tendem a se interessar cada vez mais pelo assunto e exercer seu papel de forma mais efetiva.

Esta tendência é percebida no decorrer desta pesquisa. $O$ índice de egressos que trabalham como empregados com carteira assinada ainda corresponde a 50\% do total de egressos entrevistados, mas o índice de egressos que hoje são empresários é considerável $(29,75 \%)$.

No Brasil existem instrumentos que possibilitam avaliar a qualidade dos cursos de graduação oferecidos. O Exame Nacional dos Cursos (ENC), que ficou mais conhecido pelo nome de Provão, e hoje foi substituído pelo Enade, é um desses instrumentos, e a partir disso, o MEC começou a demonstrar para a sociedade que a educação está sendo avaliada, e isso gerou expectativas no mercado. Isso mostra que este é um momento de crescimento no setor educacional, especialmente do ensino superior, o que leva à competitividade.

Em relação ao curso de administração da Unioeste, este alcançou nota máxima no Enade (resultado esperado 5 e resultado alcançado 5), comprovando sua visível qualidade e indicando assertividade no trabalho de todos envolvidos neste processo de ensinoaprendizagem. Isso torna o curso de administração da Unioeste qualificador entre as 3537 instituições de ensino que ofertam o curso de administração no Brasil onde apenas 13 delas atingiram este patamar.

Os cursos de graduação, de um modo geral acompanham de perto a evolução do mercado de trabalho, por isso, o curso de administração encontra-se em estágio de maturidade considerando um ciclo de vida e ao mesmo tempo, sofreu diversas mudanças ao longo do tempo. Muitas dessas mudanças são relativas ao diferente enfoque necessário ao mercado de trabalho.

O ponto chave do trabalho em questão está na evolução profissional dos egressos do curso de administração da Unioeste e até onde sua formação acadêmica teve influência neste aspecto. Neste sentido, é possível perceber, que a evolução profissional está muito ligada ao nível salarial e ao status. E este se tornou um fator que normalmente dimensiona o "sucesso" profissional dos indivíduos que em relação ao presente trabalho teve uma ótima evolução.

Por isso, o grau de satisfação com a carreira seguida normalmente está muito relacionada ao sucesso profissional conquistado em virtude da carreira, e na modernidade vem sendo revestido de novos significados. Por ser algo muito intrínseco e depender de cada indivíduo a satisfação não tem um significado único, mas é um objetivo comum. A satisfação 
pessoal, normalmente, é relacionada ao dinheiro, o prestígio e o status e varia conforme os valores pessoais dos indivíduos.

Um ponto que importante de melhoria aconteceu a partir da mudança de foco do curso, que por muitos anos esteve em Administração Agroindustrial. Acreditava-se que a região oeste do Paraná era essencialmente agrícola e o mercado voltado ao agronegócio, e através da pesquisa comprova-se que este é um equívoco, pois apenas 4,93\% dos egressos trabalham com agronegócio. Sabe-se ainda que o setor predominante em Cascavel é o setor de serviços e tem uma atuação de $30,68 \%$ dos egressos do curso de administração.

Os egressos, portanto, formam uma ponte entre a universidade, a sociedade $\mathrm{e}$ as empresas, repassando os conhecimentos vividos aos futuros ingressantes no mercado de trabalho. Ao mesmo tempo, contribuem para melhorar a qualidade da escola por onde passaram se tornando a imagem da própria instituição, a qual estabelece um esforço coordenado e dá direção a quem trabalha, pois quando todos os indivíduos sabem para onde estão indo e qual é a sua contribuição no todo organizacional, as metas tornam-se conjuntas e a cooperação acontece simultaneamente, sendo estes objetivos financeiros ou não.

\section{REFERÊNCIAS}

AZZI, Roberta Gurgel. As mudanças no ensino superior brasileiro em discussão no interior do FENPB: informes sobre atividades já realizadas. 2007. Disponivel em: $<$ http://www.abepsi.org.br/web/boletim-especial.aspx >- Acesso em abr/2009.

CANOPF, Liliane; FESTINALLI, Rosane C.; e ICHIKAWA, Elisa Y.. A expansão do ensino superior em Administração no sudoeste do Paraná: reflexões introdutórias. Revista de

Administração Contemporânea. Versão online. V. 9 n $^{0}$ 3. Curitiba, jul/set2005. p. 79-97. Disponível em: www.scielo/scielo.php?pid=S141565552005000300005\&script $=$ sci_arttext Acesso em set/2012.

CERVO, A. L.; BERVIAN, P. A. Metodologia científica.6 ed., São Paulo: Prentice Hall, 2003.

CLOSS, Lisiane Quadrado e ANTONELLO, Claudia Simone. Aprendizagem

Transformadora: Integrando a Reflexão Crítica na Formação Gerencial. Revista Gestão.Org - Número Especial I ENEPQ, p. 59-69: Novembro. 2008.

CRUZ, Carlos Henrique de Brito. Universidade pública e desenvolvimento. Folha Opinião.

21 de julho de 2001. Disponível em: <http://www.ifi.CRUZ,

2001.br/ brito/artigos/fsp2106200109.pdf>. Acessado em 11\04\2009.

GASSET, José Ortega y. Missão da universidade. Rio de Janeiro: Editora UERJ, 1999. 
GRACIOSO, Francisco. Propaganda institucional: nova arma estratégica das empresas. São Paulo: Atlas, 1995.

INEP -Instituto Nacional de Estudos e Pesquisas Anísio Teixeira. Diretoria de Estatísticas e Avaliação da Educação Superior (DAES). Censo de Educação Superior. Disponível em: http:<//www.inep.gov.br/superior/censosuperior/>. Acesso em 13 de maio de 2009.

LIMA, Solange Moreira Dias de. O Perfil do Administrador do presente, face as Novas Tecnologias da Informação. 05/10/2002. Disponível em

$:<$ www.portaldomarketing.com.br/artigos $>$. Acesso em 12 de março de 2009.

LOPES, P. Reflexões sobre as bases da formação do administrador profissional no ensino de graduação. Anais do Encontro Anual da ANPAD. 26. Campinas, ANPAD, 2002. p. 03-04

MALHOTRA, K. Naresh. Pesquisa de Marketing: Uma orientação aplicada. Porto Alegre: Bookman, 2001.

MARCONI; M. A; LAKATOS, E. M. Fundamentos de metodologia científica. 5 ed. São Paulo: Atlas , 2003.

MELLO, Sebastiao Luiz de; MELO JUNIOR, José Samuel de Miranda; MATTAR, FauzeNajib. Perfil, formação, atuação e oportunidades de trabalho do administrador: pesquisa nacional. 5.ed. Brasilia: CFA, 2011.

MINTZBERG, H. MBA? Não, obrigado: uma visão crítica sobre a gestão e o desenvolvimento de gerentes. Porto Alegre: Bookman, 2006.

NICOLINI, A. Qual será o futuro das fábricas de administradores? Anais do Encontro Anual da ANPAD. 25. Campinas, 2001. p.02-03

NISKIER, A. LDB - a nova lei da educação. 5. ed. Rio de Janeiro: Consultor, 1997. p. 1-35.

RIBEIRO, Nelson de Figueiredo. Administração acadêmica universitária: a teoria, o método. Apresentação de Clóvis Cunha da Gama Malcher. Rio de Janeiro: Livros técnicos e científicos, 1977.

RINALDI, Rúbia Nara. Adaptação estratégica em universidades públicas: o caso da Unioeste Cascavel. Cascavel: Edunioeste, 2002.

ROJO, C. A. Planejamento estratégico: modelo para simulação de cenários. Cascavel: Assoeste, 2006.

SANTOS, Heloisa Occhiuze dos. Ideário Pedagógico de Formação Profissional: uma perspectiva de Anísio Teixeira. Revista Espaço Acadêmico. Ano II, No 16 , Setembro de 2002. Disponível em: <www.espacoacademico.com.br/016/16col_heloisa.htm> acessado em 29 de abril de 2009. 
SILVA, Fabio Q. B. da.Cooperação empresa/universidade: contexto, análise e perspectivas. Disponível em <www.di.ufpe.br/ srlm/secomu96/fabio.htm>Acesso em abr/ 2009a.

SILVA, Maria Georgia Malheiros. Marketing como ferramenta para a ciência: Marketing científico. Disponível em <www.webartigos.com> acessado em 15 de abril de 2009b.

VOGT, Carlos. A universidade e seus desafios. Revista Com Ciência-Reforma Universitária. 2004. Disponível

em:http:<www.comciencia.br/reportagens/2004/09/01.shtml> Acesso em 30 de abril de 2009. 